\title{
The Case of Fetal Maceration in Two Different Bitches
}

\author{
Bozkurt G, Sidekli O*, Aksoy G, Cortu A and Agaoglu AR \\ Department of Obstetrics and Gynecology, Faculty of Veterinary Medicine, Mehmet Akif Ersoy University, Burdur, \\ Turkey
}

${ }^{*}$ Corresponding author: Sidekli O, Department of Obstetrics and Gynecology, Faculty of Veterinary Medicine, Mehmet Akif Ersoy University, Burdur, Turkey, Tel: 00905076268412, E-mail: vethek.ozge@gmail. com

Citation: Bozkurt G, Sidekli O, Aksoy G, Cortu A, Agaoglu AR (2018) The Case of Fetal Maceration in Two Different Bitches. J Vet Sci Ani Husb 6(1): 104. doi: 10.15744/2348-9790.6.104

Received Date: January 26, 2018 Accepted Date: February 26, 2018 Published Date: February 28, 2018

\begin{abstract}
Prenatal development consists of three stages in dogs. These stages are called preimplantation, embryonic and fetal period respectively. Embryonic or fetal losses may occur as a result of any causes that damage embryo or fetus during prenatal development period. These losses are called resorption, abortion, mummification and maceration according to the stage of pregnancy. Fetal maceration is often observed in cattle, but also can occur in other domestic animals. The incidence is quite low in bitches. The materials of this case were two bitches in different breeds that are Pointer and Golden retriever. They were brought to Clinics of Obstetrics and Gynecology by their owners with the complaints of growth in their abdomen, increase in weight and decrease in movements at different times. Firstly, detailed anamnesis was taken from their owners. As the mating status of both bitches is unknown, the probabilities of pregnancy and pregnancy pathologies have been neglected in the clinics previously referred to with the same complaints and both bitches were diagnosed with obesity by considering breed predisposition. In this context, it was learned that there was no treatment except for the suggestion of on low energy content foods and exercises however no healthy improvements were observed in both bitches. Gynecological, ultrasonography and radiographic examinations, whole blood and serum biochemistry analysis were performed on both bitches after anamnesis was taken. When the findings of the analysis and examination were evaluated, it was concluded that the fetuses were autolyzed in the uterus without being aborted. It was concluded to perform ovariohysterectomy operation on both dogs for treatment. When the removed uterus tissues were examined, it was seen that both bitches had fetal maceration.
\end{abstract}

Keywords: Uterus; Fetal maceration; Juvenile losses; Bitches

\section{Introduction}

Prenatal development consists of three stages in bitches. When the day of ovulation is accepted as day zero; the first period is preimplantation period including the time from fertilization to blastocyst formation (2-17th day), the second period is the embryonic period beginning with the blastocyst in endometrial implant (19-35th day) and the third period is called the fetal period (35th day-birth) in which growth is accelerated and characteristic features of the fetus can be defined [1,2]. Embryonic or fetal losses may occur as a result of any causes that damage embryo or fetus during prenatal development period. Embryonic or fetal deaths may result in resorption, mummification, maceration or abortion depending on the period of the gestation [3].

Fetal maceration is characterized by fetal death and incomplete abortion to occur as a result of uterine inertia depending on any reason [4]. The cervix uterus is partially or completely open during abortion; consequently, bacteria or other contagions can easily enter through the vagina to uterine lumen. After bacterial contamination has occurred, fetal emphysema begins within $24-48$ hours and, maceration occurs within 3-4 days [5,6]. The fetus or fetuses are putrefied and autolyzed with different degrees according to the pathogenicity of the bacteria. If maceration occurs after bone formation, autolysis could continuous until all fetal soft tissues become autolyzed thus only remains bones [1,4,7]. Bone fragments remaining in uterus could be embedded into the uterine wall [4], which causes chronic endometritis or severe damage of endometrium. Fetal maceration is most often observed in cattle although it could be observed in other species. The incidence is quite low in bitches [7].

\section{Case History}

Two bitches were used in the present case study, which were 6 and 7 years old Pointer and Golden retriever breeds respectively, brought to Mehmet Akif Ersoy University, Faculty of Veterinary Medicine Department of Obstetrics and Gynecology Clinic by owners at different times. They had complaints of abdominal enlargement, increase in weight and reduction in movements. Clinical examinations revealed a decrease in the movement, due to enlargement of the stomach and abdominal defenses in Pointer bitch, also the complaints of polyuria and polydipsia have prepared the groundwork for a more detailed investigation of the patient. 
Other bitch with general condition disorder and polydipsia complaint which was diagnosed obesity at a different clinic nearly one month ago, was brought to our clinic by owners. Impairment of general health conditions was thought to be due to be caused by systemic problem except obesity. A detailed clinical, hematological and biochemical examinations of both patients were done. Diagnosis was supported by radiographic and ultrasonographic imaging techniques.

\section{Physical and Gynecological Examination}

In clinical examinations, body temperature $\left(39.5^{\circ} \mathrm{C}, 36.4^{\circ} \mathrm{C}\right)$, pulse rates $(78,74 / \mathrm{min}$.) and respiratory rate $(34,26 / \mathrm{min})$ of Pointer and Golden retriever bitches were measured respectively. A detailed anamnesis was taken and physical examinations were done of both bitches (Table 1). The most obvious symptoms were enlargement in the abdominal region and the presence of mild pain in both bitches.

\begin{tabular}{|c|c|c|}
\hline Symptoms & Pointer & Golden retriever \\
\hline General condition & Good & Poor \\
\hline Abdominal palpation signs & $\begin{array}{c}\text { No pain Rigid } \\
\text { masses }\end{array}$ & $\begin{array}{c}\text { Mild pain } \\
\text { Fluctuant masses }\end{array}$ \\
\hline Body weight & $24 \mathrm{~kg}$ & $35 \mathrm{~kg}$ \\
\hline Abdominal strain & Enlargement & Enlargement \\
\hline Vomiting & Absent & $\begin{array}{c}\text { Less than } 2 \text { times } \\
\text { per a day }\end{array}$ \\
\hline Polyuria (>50 $\mathbf{~} \mathbf{l} / \mathbf{k g ~ q 2 4 h )}$ & + & + \\
\hline Polydipsia $(>\mathbf{8 0} \mathbf{~ m l} / \mathbf{k g ~ q 2 4 h )}$ & + & + \\
\hline Appetite & Normal & $\begin{array}{c}\text { Anorexia more } \\
\text { than } 15 \text { days }\end{array}$ \\
\hline
\end{tabular}

Table 1: Anamnesis and physical examination findings in bitches

There was no pathological vaginal incharge observed in Pointer bitch while malodorous, irritated, dark brown vaginal incharge has been observed in Golden retriever bitch in vaginal examinations. According to their anamnesis, Pointer and Golden retriever bitches were showed last estrus time respectively 1.5 years ago and 7 month ago, but mating status of both bitches are unknown in these periods.

\section{Complete blood and serum biochemical examinations result}

Blood samples were collected from Cephalica antebrachii. Complete blood count and serum biochemical analysis of samples were done using Abacus Junior-Vet and Autoanalyzer-mod Gesan Chem-200 devices, at the Diagnostic Laboratory of Clinics (Table 2 and 3).

\begin{tabular}{|c|c|c|c|c|c|}
\hline $\begin{array}{c}\text { Hematology } \\
\text { parameters }\end{array}$ & Results & $\begin{array}{c}\text { Reference } \\
\text { values }\end{array}$ & $\begin{array}{c}\text { Biochemistry } \\
\text { parameters }\end{array}$ & Results & $\begin{array}{c}\text { Reference } \\
\text { values }\end{array}$ \\
\hline RBC & 7.27 & $5.5-8.5$ & UREA & 32 & $8-28$ \\
\hline HGB & 15.8 & $12-18$ & CRE & 0.9 & $0.5-1.7$ \\
\hline HCT & 44.56 & $37-55$ & GOT & 18 & $13-15$ \\
\hline WBC & 13.05 & $6-17$ & GPT & 65 & $10-109$ \\
\hline LYM & 4.85 & $1-4.8$ & GGT & 11.3 & $1-9.7$ \\
\hline MID & 0.73 & $0.2-1.5$ & ALP & 98 & $1-114$ \\
\hline PLT & 201 & $200-500$ & & & \\
\hline
\end{tabular}

RBC: Red blood cells, HGB: Hemoglobin; HCT: Hematocrit; WBC: White blood cells; LYM: Lymphocytes; MID: Monocytes; PLT: Platelets; UREA: Urea; CREA: Creatinin; GOT: Urine amylase; GPT: Alanine transaminase; GGT: Gama glutamyl transaminase; ALP: Alkaline phosphatase

Table 2: Hematological and biochemical analysis results of Pointer bitch

\begin{tabular}{|c|c|c|c|c|c|}
\hline $\begin{array}{c}\text { Hematology } \\
\text { parameters }\end{array}$ & Results & $\begin{array}{c}\text { Reference } \\
\text { values }\end{array}$ & $\begin{array}{c}\text { Biochemistry } \\
\text { parameters }\end{array}$ & Results & $\begin{array}{c}\text { Reference } \\
\text { values }\end{array}$ \\
\hline RBC & 8.51 & $5.5-8.5$ & UREA & 85 & $8-28$ \\
\hline HGB & 18.7 & $12-18$ & CRE & 0.72 & $0.5-1.7$ \\
\hline HCT & 55.00 & $37-55$ & GOT & 21.7 & $13-15$ \\
\hline WBC & 26.04 & $6-17$ & GPT & 50 & $10-109$ \\
\hline LYM & 1.23 & $1-4.8$ & GGT & 12 & $1-9.7$ \\
\hline MID & 0.93 & $0.2-1.5$ & ALP & 446 & $1-114$ \\
\hline PLT & 321 & $200-500$ & & & \\
\hline
\end{tabular}

RBC: Red blood cells; HGB: Hemoglobin; HCT: Hematocrit; WBC: White blood cells; LYM: Lymphocytes; MID: Monocytes; PLT: Platelets; UREA: Urea; GOT: Urine amylase; GPT: Alanine transaminase; GGT: Gama glutamyl transaminase; ALP: Alkaline phosphatase Table 3: Hematological and biochemical analysis results of Golden Retriever bitch 


\section{Ultrasonography and radiography examinations}

The genital tracts were examined in transabdominal ultrasonography of both bitches showed that anechoic and hypoechoic areas were seen clustered within the uterus. Firstly, it was thought that these areas could be structures belonging to the neatly sorted offspring. But later, when radiographic examination revealed that it was understood that these areas were fetal bone fragments within uterus (Figure 1).
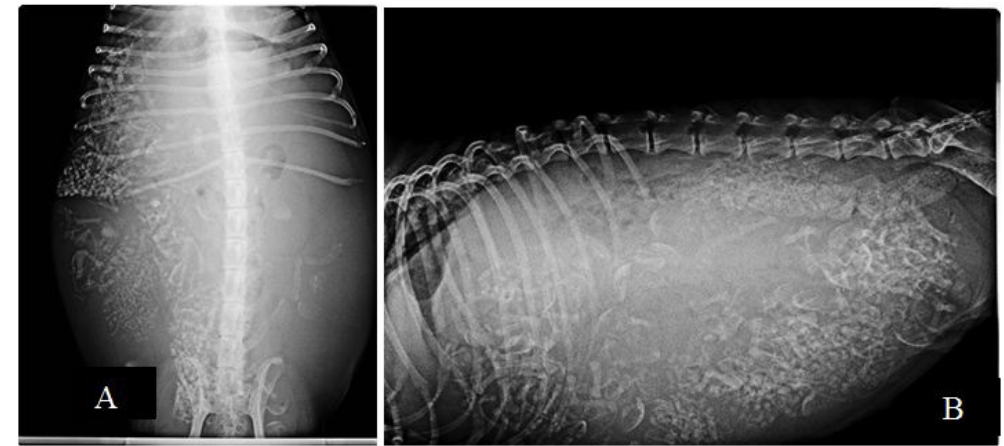

Figure 1: (A) Pointer bitch's ventrodorsal abdominal radiograph that showing debris of fetuses' bones; (B) Golden retriever bitch's laterolateral abdominal radiograph that showing debris of fetuses' bones

When the findings of the analysis and examinations were evaluated, it was concluded that the fetuses were autolyzed in the uterus without being aborted. It was decided to perform ovariohysterectomy operation on both bitches for treatment.

\section{Operative interventions}

Standard preoperative preparations for ovariohysterectomy surgery were followed. Pre-anesthetic medication consisted of atropine sulfate $(0.04 \mathrm{mg} / \mathrm{kg}, \mathrm{SC})$. Anesthesia was induced by xylazine $\mathrm{HCl}\left(2.0 \mathrm{mg} / \mathrm{kg}\right.$, - Rompun ${ }^{\oplus}$, Bayer) followed by ketamine $\mathrm{HCl}$ (10.0 $\mathrm{mg} / \mathrm{kg}$, - Alfamine ${ }^{\oplus}$, Egevet) were administered intramuscularly. The median line was preferred for operative approach in both bitches. During the operation, it was observed that the uteruses partially got thinner and also growing in volume. In addition, in the palpation of the uteruses, some areas of fluctuant, partially hardened were found. When the removed uterus tissues were examined, it was concluded that both bitches had fetal maceration.

The abdominal cavities were washed with sterile $\% 0.9 \mathrm{NaCl}$ saline solutions and respectively peritoneum and all muscle layers and the skin were closured with simple and horizontal mattress sutures respectively. Protective bandages were applied so as not to restrict the movement of the both bitches (Figure 2).
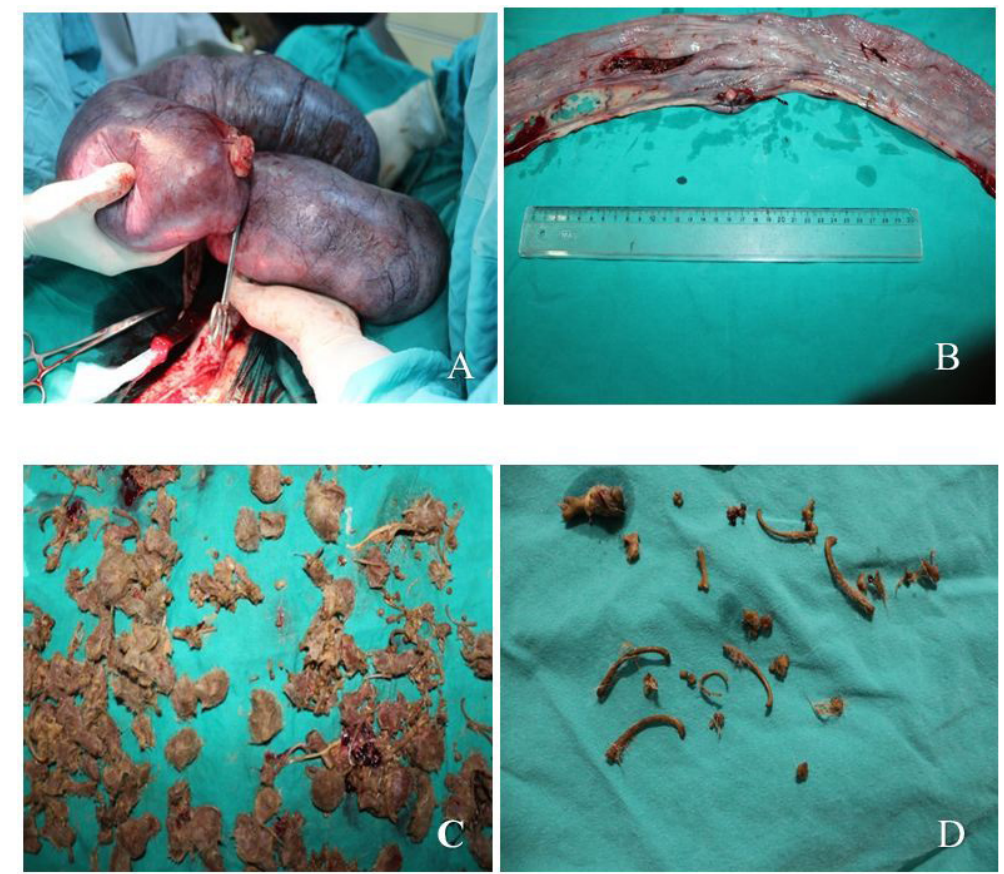

Figure 2: (A) Macroscopic appearance of the uterus during ovariohysterectomy; (B, C, and D) Macroscopic appearance of the uterus after ovariohysterectomy and retained fetal bones and tissues 


\section{Post-operative care}

After surgery, bitches were kept in individual cages in order to restrict their movement.

Dogs were treated post-operatively with amoxicillin-clavulanic acid (10 mg/kg, im, Synulox ${ }^{\circ}$, Zoetis) for 7 days, isotonic $0.9 \% \mathrm{NaCl}$ $(40 \mathrm{ml} / \mathrm{min})$ for 2 days. Meloxicam ( $3 \mathrm{mg} / \mathrm{kg}$, sc, Maxicam ${ }^{\circledR}$, Sanovel) was used to reduce pain and inflammation. The bandages of the both bitches were removed on the 3rd day after operation. Sutures were removed after 7 days of operations. There was no pathological condition around the incision line.

\section{Discussion}

Embryonic losses which occur in the period between implantation and formation of fetal skeleton are called as fetal resorption, later occurrences are called abortion. Failure to expel out the fetus may be due to uterus inertia, cervical spasms, abnormal fetal presentations, positions and postures, deficiencies of uterine contractions or intrauterine infections resulting in fetal mummification and maceration $[1,6,8]$.

According to the information received from the owners that bitches didn't show any signs of abortion and they have not been shown estrus for the past 1.5 years and 7 months. However, there are no definite information about the fact that mating status of bitches.

Maceration may occur as a result of microorganism-induced intrauterine infections during pregnancy. Microorganisms while cause resorption and autolysis of fetal soft tissues, non-absorbable tissues such as bone and hair remain in uterus and cannot be expelled [9]. In the present case, while there were hair and bone fragments observed as a cluster in the uteruses and, there was malodorous, purulent, dark brown fluid in the Golden retriever's uterus. These findings suggest that autolysis and resorption activities have been continued. Abnormal fetal presentations, postures and positions could facilitate the fetal maceration $[1,8]$. The cause of maceration in the golden retriever bitch was rather than uterus inertia probably due to a presentation, position, or postural disturbance of the fetus because; intensely of the bone and hair masses were in the corpus uterine region. In most cases of maceration, systemic symptoms occur because mother has toxemia and septicemia [4,9]. But there wasn't observed any systemic symptoms in Pointer bitch. This situation supported also hemogram and serum biochemistry. As the mating status of both bitches was unknown, the probabilities of pregnancy and pregnancy pathologies have been neglected in the clinics previously referred to with the same complaints and both bitches were diagnosed with obesity by considering breed predisposition [10,11]. In this context, it was learned that there was no treatment except for the suggestion of on low energy content foods and exercises however no healthy improvements were observed in both bitches.

\section{Conclusion}

As a result of missing anamnesis or examinations; it has been determined that abdominal enlargement caused by the rare occurrence of fetal maceration in dogs may be confused with other conditions causing enlargement of the abdominal region such as obesity. In addition, it has been concluded that obtaining detailed and healthy anamnesis information in such cases and using medical imaging methods are very important in terms of receiving correct diagnosis.

\section{References}

1. Drost M (2007) Complications during gestation in the cow. Theriogenology 68: 487-91.

2. Köse AM, Tekeli T (2014) Loss of juveniles during prenatal period in dogs and cats. AVKAE Derg 4: 77-85.

3. Givens MD, Marley MS (2008) Infectious causes of embriyonic and fetal mortality. Theriogenology 70: $270-85$.

4. Noakes DE, Parkinson TJ, England GCW (2003) Abnormal development of the conceptus and its conseguences In: Veterinary Reproduction and Obstetrics (8th Edn) Saunders Elsevier, USA.

5. Bhattacharyya HK, Dar SA, Fazili MR (2015) Fetal maceration in crossbred Holstein frisian hedifer. Int J Vet Sci Res 1: 1-4.

6. Serın G, Parın U (2009) Recurrent vaginal discharge causing by retained foetal bones in a bitch. Vet Med 54: 287-90.

7. Alaçam E, Doğaneli MZ (1973) Bir inekte fetal maserasyon. AÜ Vet Fak Derg 2.3: 358-61.

8. Mahla AS, Shinde S, Sachan V, Chaudhari RK, Kumawat BL, et al. (2016) A rare case of foetal maceration in bitch and its successful management. Theriogenology insight 6: 41-4.

9. Max A, Jurka P, Bartyzel BJ, Grzegrzolka B (2015) Foetal mortality in dogs and cats not related to spontaneous abortions. Folia Pomer Univ Technol Stetin, Agric, Aliment, Pisc, Zootech 316: 81-8.

10. Bland IM, Gurthrie-Jones A, Taylor RD, Hill J (2009) Dog obesity: owner attitudes and behaviour. J Prev Vet Med 92: 333-40.

11. German AJ, Holden SL, Moxham GL, Holmes KL, Hackett RC, et al. (2006) A simple, reliable tool for owners to assess the body condition of their dog or cat. J Nutr 136: 2031S-3S. 


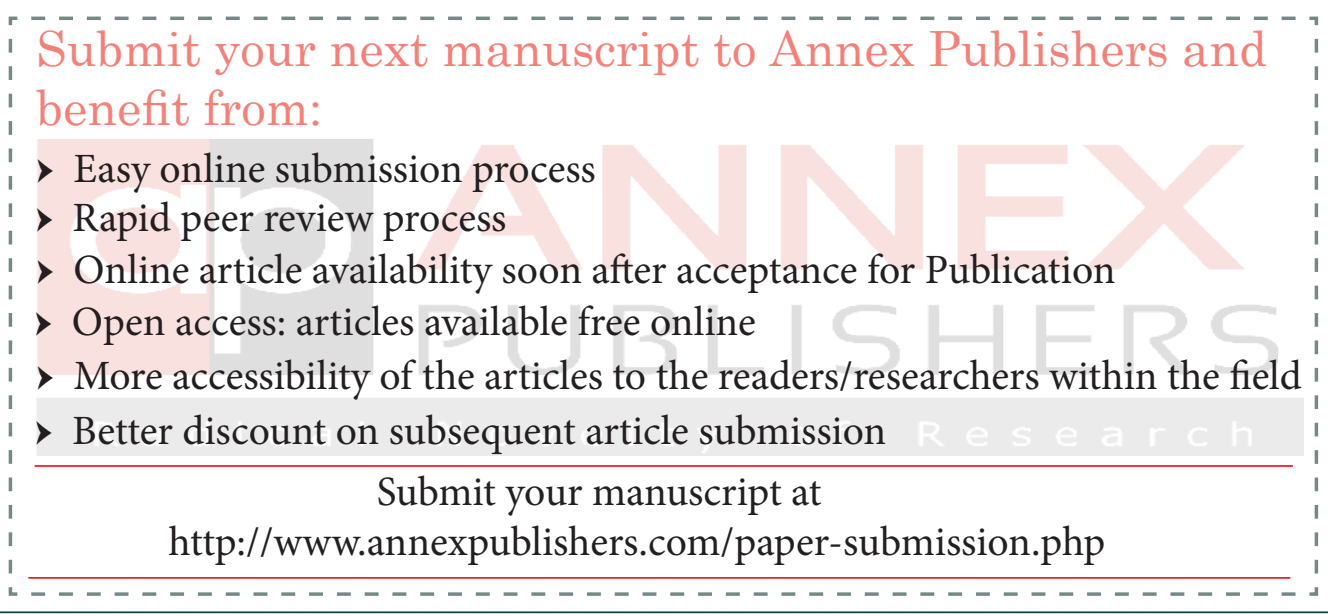

